\title{
Air travel choices in multi-airport markets
}

\author{
Jun Ishii, Sunyoung Jun and Kurt Van Dender* \\ jishii@uci.edu, sjun@uci.edu, kvandend@uci.edu
}

Department of Economics

University of California, Irvine

Irvine, CA 92697-5100

This version: 2/16/06

\begin{abstract}
We estimate a conditional logit model to measure the impact of airport and airline supply characteristics on the air travel choices of passengers departing from one of three San Francisco Bay area airports and arriving at one of four airports in greater Los Angeles in October 1995. Non-price characteristics like airport access time, airport delay, flight frequency, the availability of particular airport-airline combinations, and early arrival times are found to strongly affect choice probabilities. Marginal effects and counterfactual scenarios suggest that changes access in times affect travel choices more than changes in travel delays, and that the preferred airport differs by passenger type. In order to examine the robustness of the conditional logit model, we estimate a mixed logit model, and find that the results are similar. We attribute the similarity to our strictly defined travel market and to our distinction between leisure and business travelers, thus controlling for two important sources of consumer heterogeneity.
\end{abstract}

Keywords: airports, airlines, air travel demand, discrete choice

JEL codes: L11, L15, L93, R410

\footnotetext{
* We would like to thank for remarks, help and advice: Severin Borenstein, David Brownstone, Joe Farrell, Chuck Purvis, Marc Roddin, Frank Wolak, participants at the 2005 IOFest at U.C. Berkeley, as well as seminar participants at U.C. Davis, U.C. Santa Cruz, and K.U.Leuven. Sunyoung Jun and Kurt Van Dender gratefully acknowledge financial support from the U.S. Department of Transportation and the California Department of Transportation through the University of California Transportation Center. The usual disclaimer applies.
} 


\section{Introduction}

Many studies of competition in the airline industry define markets for air travel in terms of airport pairs. While justified in markets where both the trip origin and the destination are served by a single airport, this approach is less suitable for markets characterized by a high density of demand, where travelers often have a choice of airport at both the travel origin and destination. Large metropolitan areas (for example Boston, Chicago, Los Angeles, New York, the San Francisco Bay Area, Washington D.C.) typically are served by several nearby airports that provide flights to a similar set of destinations. The airports may be fairly close substitutes to travelers, and it is desirable to take this into account when analyzing competition in this type of market. This paper investigates how the characteristics of the choices for traveling from the Bay Area to greater L.A. in October 1995 affect the probability that travelers' choose a particular option. In particular, our data allow us to focus on non-price characteristics, such as departure and arrival airport characteristics, airline, flight frequency, travel delay, and arrival early in the day. The nonprice characteristics are found to be important co-determinants of travel choices. Fares negatively affect demand for leisure travel, but not so much for business travel.

In the type of multi-airport market that is considered here, the vertical and horizontal interactions between airlines and airports are more complex than in a single airport context, as airlines need to make choices concerning pricing and service characteristics for different, substitutable airports, and airport behavior is affected by the presence of nearby airports. ${ }^{1}$ This paper stops well short of providing an integrated model of supply and demand in multi-airport markets, but it sheds light on how the structure of demand shapes competition in such a setting. The analysis is relevant to a range of issues in the air transportation industry. Consider, for example, the ongoing trend towards increased airport independence, which is anticipated to benefit travelers through more intense competition (FAA/OST, 1999). These anticipated benefits are conditional on the substitutability of airports, which in turn depends on price and non-price characteristics of airport services. As a second example, airlines may exploit the availability of different

\footnotetext{
1 Airports may be effectively controlled by an airline, and they may maximize profit, surplus, or output. In each of these cases, spatial market power is limited by the presence of substitute airports, and this affects choices regarding capacity, access charges, and the pricing of passenger services (Van Dender, 2006).
} 
airports to engage in product differentiation and price discrimination, by offering different levels of service quality at different airports. As noted in Borenstein (1989), price discrimination can be used by airlines to segment the market, separating passengers who might switch among airports from those strongly entrenched in their airport choice.

The empirical analysis is based on a combination of datasets, among which the 1995 airline passenger survey in the San Francisco Bay Area. We estimate weighted conditional logit models as well a mixed logit model, both of which produce similar results. The main findings are that passengers traveling from the Bay Area to greater L.A. consider the departure airports (OAK, SFO, SJO) ${ }^{2}$ to be fairly close substitutes, with SFO preferred when everything else is equal. More detailed interpretations are made on the basis of calculated marginal effects and counterfactual scenarios. Our findings concerning the determinants of airport choice are that the various components of time costs associated with an airport are important. Both business travelers and leisure travelers care more about access times than about delays, but business travelers care relatively more about delays. Airline choice also depends on the quality of service (frequency of service and delays) and on fares, and early morning flights are prefered over later ones. Airport and airline dummy variables are important, pointing to residual heterogeneity that is not captured by the included airline and airport characteristics. One set of counterfactual scenarios shows that reducing relative time costs is an effective way of increasing market share of an airport and of airlines that dominate it (United Airlines in the case of SFO). A further set of counterfactual scenarios assumes that Southwest Airlines enters at SFO, where it was not actually present in October 1995. We find that Southwest increases its market share by doing so, except among leisure travelers under the further assumption that Southwest abandons its operation at OAK. This suggests that some leisure travelers have a strong preference for Southwest in OAK. ${ }^{3}$

The paper is structured as follows. Section 2 provides a review of related literature, and a description of our contributions to it. Section 3 describes the data and the results of the weighted conditional logit and mixed logit models; we present coefficient

${ }^{2}$ OAK is Oakland International airport, SFO is San Francisco International, and SJO is San Jose International.

${ }^{3}$ The counterfactuals abstract from cost effects and capacity constraints, and maintain the assumption that non-United rivals do not respond to Southwest’s actions. 
estimates and marginal effects. Section 4 discusses counterfactual scenarios that illustrate the joint impact of the estimated model. Section 5 summarizes and concludes.

\section{Literature}

Our empirical analysis is related to a relatively small literature on airport choice in a multi-airport region, where the choice for an airport may be modeled as such, or in combination with transport mode choices for ground access or with airline choices. ${ }^{4}$ The models are estimated using discrete choice techniques of varying complexity and generality, but there is wide consensus that ground access times and quality of service (often measured by flight frequencies) strongly affect the choice for a particular airport. We review some contributions that, like us, use the 1995 air passenger survey for the Bay Area airports as the central source of data on travel choices.

Pels et al. (2001) analyze the choice for an airport and an airline in the San Francisco Bay Area using a nested logit model, and find that a model where the airport is chosen first and the airline next is statistically preferred over the reverse choice structure. Using the same dataset and a nested logit model to look at the choice of access mode and airport, Pels et al. (2003) find that the mode choice patterns imply high values of time. Basar and Bhat (2002, 2004) estimate a probabilistic choice set multinomial logit model of airport choice by business travelers residing in the Bay Area. Their model allows the choice set to be constructed by travelers, in particular allowing for the possibility that travelers do not take all departure airports into account. They find that access time matters, more so than frequency, but that the effect of access time is weaker and that of flight frequency is stronger than in a standard multinomial logit model, where the choice set is exogenously given. Most recently, Hess and Polak (2004) analyze airport choice in the San Francisco Bay Area using a mixed multinomial logit specification, so allowing for random preference variation, and find that this affects the results. One suggested explanation as to why a mixed logit model performs better than the standard logit model, is that not all variation in the sensitivity of airport choice to access time is captured by observed passenger characteristics.

\footnotetext{
${ }^{4}$ The early contributions are by Skinner (1976), Harvey (1987) and Ashford and Bencheman (1987).
} 
Our analysis starts by defining a specific market for air travel, and this leads to three main differences with the reviewed work. First, we restrict attention to a specific set of destinations (four airports in or around Los Angeles), rather than lumping all destinations together as is done in the mentioned studies. In doing so, we delineate a specific market in which carriers compete directly. The particular market is served by direct flights, so that aspects of network competition (other than hub dominance, which we take to be exogenous to the market under study) are relatively unimportant. Also, unobserved variation in egress times from destination airports is lower when arrival airports are controlled for. Second, we consider a more detailed representation of flight characteristics and flight choice than earlier studies. For example, we consider differences between business and leisure travel, between peak and offpeak travel, and between early and late flights. We use information on fares and on delays at arrival and at destination airports, and we allow for airline specific effects. Finally, we correct for choice based sampling, more particularly for over-sampling of passengers departing from San Jose airport, in order to obtain an estimated model that is suitable for marginal effects calculation and counterfactual simulation.

While our analysis focuses on airport and airline choice, we think of it as being informative to analyses of competition in the air transportation industry. While much of the literature on the topic focuses on airline competition, some studies recognize the importance of airport characteristics. In particular, researchers have focused on the impact of "airport dominance" and airport congestion on airline competition. Key papers on the role of airport dominance in airline competition include Borenstein (1989, 1991), Berry (1990, 1992), Morrison and Winston (1989), Evans and Kessides (1993), and Berry, Carnall and Spiller (1997). ${ }^{5}$ A central idea here is that larger airport presence increases the value to consumers of frequent flier programs and other airline marketing programs, and this enables airlines to charge higher fares. However, the ability of airlines to use airport dominance to extract consumer surplus will depend on the presence of substitute airports: in markets served by multiple airports, the dominance of any one airport by an airline does

${ }^{5}$ Of particular relevance is the Morrison and Winston (1989) study which uses an empirical strategy similar to ours. They estimate the impact of airport presence on airline choice by applying a multinomial logit model to DB1A passenger data. Our study can be considered an extension of theirs - expanding the choice set to include airport choice. Our data also provide more information about the passengers than DB1A. 
not necessarily preclude other airlines from offering a similar array of flights. This type of effect is discussed in Morrison (2001), who finds that the presence of Southwest at nearby airports disciplines carriers at any particular airport, but the effect is weaker compared to the case where Southwest competes in the same airport. Borenstein (2005, table 2) provides suggestive evidence that airport competition may reduce the impact of airport dominance on airfare, in that hub airports in metropolitan areas served by multiple airports (e.g. San Francisco Bay Area, Los Angeles, Chicago, New York, D.C.) seem to be associated with lower hub premiums than hub airports in single airport markets (e.g. Charlotte, Cincinnati, Detroit, Memphis Minneapolis). ${ }^{6}$

A different strand of the air transportation literature studies service quality competition, with an emphasis on on-time performance, and starting from the basic observation that flights into or out of certain airports are prone to travel delay more than others. Apart from natural causes (e.g. fog at San Francisco), airport congestion can contribute to travel delay, with hub airports particularly congested as airlines seek to maximize economics of traffic density (scope). This is demonstrated in Brueckner and Spiller (1994) and Mayer and Sinai (2003). Mazzeo (2003) finds that on-time performance is worse (delays are more common and longer) on concentrated routes, suggesting that airlines may use airport dominance to extract surplus not only through higher airfares but also through cost savings associated with the offering of lower quality service. Here too, however, the availability of substitute airports may provide an incentive for dominating airlines to offer higher quality service. In this context, Januszewski (2004) estimates the value that passengers attach to on-time performance. Using an exogenous shock to the on-time arrival of flights to LaGuardia, she finds that longer delays imply lower prices, and that the size of the effect depends on the availability of substitutes: when

\footnotetext{
6 Airport choice has implications for the empirical literature on airline entry, where increased attention has been brought to the issue of low-cost carriers, most notably Southwest, entering the markets of incumbent, hub-and-spoke carriers. Recent research includes Ito and Lee (2004) and Goolsbee and Syverson (2005). If city airports are imperfect substitutes, they are a form of product differentiation for the airline. Given that low cost carriers often enter the adjacent, non-hub airport in major metropolitan areas, current studies may underestimate the change in market share and incumbent response effected by the entry of a low cost carrier at the hub airport. One of our counterfactual exercises addresses these issues.
} 
substitute flights are available at the same or at competing airports, changes in service quality have larger effects on prices. ${ }^{7} \quad$ Flights at the same airport are closer substitutes, and therefore have a larger effect. In addition, the effects are larger for business travelers, presumably because they strongly dislike schedule delays.

\section{Estimating an airport and airline choice model for air travel from the San Francisco Bay Area to greater Los Angeles in 1995}

\subsection{Data and basic specification}

Our data describe the choice set, the actual choices, and the main time and money costs associated with the choice alternatives, for passengers traveling by air from the San Francisco Bay Area to greater Los Angeles during two weeks of October 1995. Specifically, we observe the choice of departure airport, arrival airport, carrier, peak or offpeak departure, and early or late flight. ${ }^{8} \quad$ The time cost components include the driving time from the initial origin to the airport, the expected flight delays at the departure airport and at the arrival airport, and the schedule delay cost as approximated by the frequency of flights per airline per airport. ${ }^{9}$ The money cost is an approximation of the flight fare.

Because of data limitations, fares are measured at a much more aggregated level than other flight characteristics, and may be different from actual transaction prices. Our use of fare information is largely restricted to comparing average differences across flight choices; precise estimation of trade-offs between time and money (i.e. estimating values of time) is not possible. Lastly, we have information on a set of socio-demographic variables, including whether passengers travel for business or leisure purposes, the exact location of departure in the Bay Area, whether travelers are residents of or visitors to the Bay Area, and

7 The overall effect is estimated at \$1.16 per minute of delay, increasing to $\$ 1.55$ when there is competition.

${ }^{8}$ Peak hours are from 6-9 am and 3 - 6 pm; all other hours offpeak. Early flights at an L.A. airport are those arriving within a time interval defined by the earliest arriving flight at that airport, plus 30 minutes. Late flights are those arriving at an airport in a time interval defined by the latest arriving flight, minus 30 minutes.

${ }^{9}$ We do not include flight times. Since all passengers fly to greater LA, the variation in flight times can be expected to be minimal. Similarly, we do not include airport egress times and travel times to the final destination, but the variation is likely to be relatively small as we focus on a single market and control for the arrival airport. 
the travelers' income group.

The dataset is composed from various sources, the primary of which is the Airline Passenger Survey as conducted in August and October 1995 by the Metropolitan Transportation Commission (MTC) in collaboration with SFO, SJC, OAK, and Sonoma County Airport (STS). ${ }^{10}$ The survey contains a purposely large number of interviews conducted at SJC, but passengers were randomly interviewed at each airport. We correct for choice based sampling at the level of the airport in the estimation. After omitting observations because no fare is reported for the flight or no match could be made with the flight schedule data, because non-car access, or because no income was reported, 1,752 observations remain, of which 935 are business travelers and 817 are leisure travelers. The airline passenger survey is combined with several secondary sources. First, the 1998 car travel times from a passenger's initial origin in the Bay Area to the airports are derived from the MTC's transportation network model. ${ }^{11}$ Second, the summary of the Origin and Destination Survey (DB1A) as provided by Severin Borenstein provides aggregate fare data, as well as weights that correct for choice based sampling. ${ }^{12}$ Third, Airline Online Performance Data from the Bureau of Transport Statistics provide information on delays at the level of the origin and destination airports. ${ }^{13}$ Fourth, the Worldwide Through Flight Schedules Database obtained from OAG is used to construct passengers' choice sets. We assume that the complete set of flights was actually available to passengers at the time they purchased a ticket.

${ }^{10}$ http://www.mtc.dst.ca.us/datamart/airpass1.htm. A first wave of the survey took place in August 1995 and a second one in October 1995. The August survey reports zero passengers departing from OAK using United Airlines (UA), which contrasts with other sources (OAG and T-100) that indicate a substantial presence of UA at OAK in August of 1995. Since our analysis considers airport and airline choice, it seemed appropriate to exclude the August data.

11 ftp://ftp.abag.ca.gov/pub/mtc/planning/forecast/RVAL98/

12 The weights obtained from DB1A were validated against T-100 data. T-100 is an alias for the 'Air Carrier Statistics Databank', based on 'Form 41 Traffic' collected by the BTS. T-100 data are segment based, but since the travel market considered here is served by direct flights, the market shares of DB1A and T-100 should be similar.

13 http://www.transtats.bts.gov. 
We first estimate a weighted conditional logit model (Manski and Lerman, 1977) defined over travel choices that are a combination of departure airport, arrival airport, airline, and peak or off-peak travel. The choices are conditional on the passengers accessing the airport of choice by car and flying to greater Los Angeles. An example of a particular choice alternative is a flight from SFO to LAX with UA during peak hours; a different option would be a flight from OAK to SNA with WN (Southwest) during the offpeak. For our basic specification, a passenger's choice is modeled as the maximization of the indirect utility function (1). Let the following sets denote departure airports, arrival airports, airlines, and time periods:

$$
\begin{aligned}
& i \in\{\text { OAK, SFO, SJC }\} \\
& j \in\{B U R, L A X, \text { ONT, SNA }\} \\
& k \in\{U A, \text { WN, Other }\}, \text { where Other }=\{A S, D L, H P, Q Q, U S\} \\
& t \in\{\text { Peak, Offpeak }\}
\end{aligned}
$$

The indirect utility of a specific alternative then is :

$$
\begin{aligned}
V_{i, j, k, t} & =\sum_{i \neq S F O} \beta_{i} D_{i}+\sum_{j \neq L A X} \beta_{j} D_{j}+\sum_{k \neq \text { Other }} \beta_{i} D_{i} \\
& +\beta_{1} \text { Fare }+\beta_{2} \text { Freq. }+\beta_{3} \text { Access }+\beta_{4} \text { Delay } \\
& +\beta_{5} \text { Inc_group } \_2+\beta_{6} \text { Inc_group_3 } \\
& +\sum_{j} \beta_{\text {early }, j} D_{\text {early }, j}+\sum_{j} \beta_{\text {late }, j} D_{\text {late }, j} \\
& +\varepsilon_{i j k t}
\end{aligned}
$$

The specification is estimated in a conditional logit model for all. for business and for leisure travelers. The distinction between passenger types is relevant, so we treat the separate estimates as the preferred ones, and omit the results for "all passengers" for the sake of brevity. Using the same data, we estimate a mixed logit model for business and leisure travelers, assuming normal mixing distributions over dummy variables for departure airports and airlines, and over the fare and time cost variables. The mixed logit model relaxes the strict substitution patterns imposed by the conditional logit model (Train, 2003), so its results inform us on the impact of those restrictions. 
Table 1a Summary statistics for business passengers (935 observations)

\begin{tabular}{|c|c|c|c|c|c|}
\hline Variable & Description & Mean & Std.Dev. & Min & Max \\
\hline$\overline{\text { sjc }}$ & sjc=1 if departure airport is SJC & 0.576 & 0.494 & 0 & 1 \\
\hline oak & oak $=1$ if departure airport is OAK & 0.284 & 0.451 & 0 & 1 \\
\hline wn & $\mathrm{wn}=1$ if airline is $\mathrm{WN}$ (southwest airlines) & 0.691 & 0.462 & 0 & 1 \\
\hline ua & ua $=1$ if airline is UA (united airlines) & 0.164 & 0.370 & 0 & 1 \\
\hline bur & bur $=1$ if arrival airport is BUR & 0.212 & 0.409 & 0 & 1 \\
\hline ont & ont $=1$ if arrival airport is $\mathrm{ONT}$ & 0.151 & 0.358 & 0 & 1 \\
\hline sna & $\mathrm{sna}=1$ if arrival airport is SNA & 0.226 & 0.418 & 0 & 1 \\
\hline fare & Average Coach Airfare (\$ in 1995) & 59.009 & 12.359 & 50 & 182 \\
\hline freq & Average number of flights per hour & 1.032 & 0.801 & 0.167 & 4 \\
\hline accetime & Access time (minutes) & 24.142 & 20.008 & 1.7 & 125.1 \\
\hline tdelay & Sum of average departure delay and arrival delay & 10.374 & 6.529 & 1.664 & 28.275 \\
\hline incgroup2 & Fare * income group2 $(\$ 75,000-\$ 149,000)$ & 46.803 & 26.449 & 0 & 182 \\
\hline incgroup3 & Fare * income group3 $(\$ 150,000$ or more $)$ & 9.867 & 22.794 & 0 & 108 \\
\hline earBUR & Early arrival at Burbank & 0.029 & 0.168 & 0 & 1 \\
\hline earLAX & Early arrival at Los Angeles & 0.074 & 0.262 & 0 & 1 \\
\hline earONT & Early arrival at Ontario & 0.039 & 0.193 & 0 & 1 \\
\hline earSNA & Early arrival at Santa Anna & 0.029 & 0.168 & 0 & 1 \\
\hline latBUR & Late arrival at Burbank & 0.006 & 0.080 & 0 & 1 \\
\hline latLAX & Late arrival at Los Angeles & 0.160 & 0.367 & 0 & 1 \\
\hline latONT & Late arrival at Ontario & 0.042 & 0.200 & 0 & 1 \\
\hline latSNA & Late arrival at Santa Anna & 0.021 & 0.145 & 0 & 1 \\
\hline Table 1b & \multicolumn{5}{|c|}{ Summary statistics for leisure passengers (817 observations) } \\
\hline Variable & Description & Mean & Std.Dev. & Min & Max \\
\hline$\overline{\text { sjc }}$ & sjc=1 if departure airport is SJC & 0.355 & 0.479 & 0 & 1 \\
\hline oak & oak=1 if departure airport is OAK & 0.512 & 0.500 & 0 & 1 \\
\hline wn & $\mathrm{wn}=1$ if airline is $\mathrm{WN}$ (southwest airlines) & 0.703 & 0.457 & 0 & 1 \\
\hline ua & ua= 1 if airline is UA (united airlines) & 0.179 & 0.383 & 0 & 1 \\
\hline bur & bur $=1$ if arrival airport is BUR & 0.190 & 0.392 & 0 & 1 \\
\hline ont & ont $=1$ if arrival airport is ONT & 0.162 & 0.368 & 0 & 1 \\
\hline sna & $\mathrm{sna}=1$ if arrival airport is SNA & 0.138 & 0.345 & 0 & 1 \\
\hline fare & Average Coach Airfare (\$ in 1995) & 56.266 & 8.997 & 50 & 108 \\
\hline freq & Average number of flights per hour & 0.626 & 0.410 & 0.083 & 2 \\
\hline accetime & Access time (minutes) & 29.887 & 23.365 & 2.6 & 173.9 \\
\hline tdelay & Sum of average departure delay and arrival delay & 12.508 & 6.851 & 1.664 & 28.275 \\
\hline incgroup2 & Fare * income group2 $(\$ 75,000-\$ 149,000)$ & 32.988 & 28.923 & 0 & 108 \\
\hline incgroup3 & Fare * income group3 $(\$ 150,000$ or more $)$ & 6.407 & 18.440 & 0 & 76.4 \\
\hline earBUR & Early arrival at Burbank & 0.026 & 0.158 & 0 & 1 \\
\hline earLAX & Early arrival at Los Angeles & 0.104 & 0.305 & 0 & 1 \\
\hline earONT & Early arrival at Ontario & 0.047 & 0.211 & 0 & 1 \\
\hline earSNA & Early arrival at Santa Anna & 0.022 & 0.147 & 0 & 1 \\
\hline latBUR & Late arrival at Burbank & 0.012 & 0.110 & 0 & 1 \\
\hline latLAX & Late arrival at Los Angeles & 0.193 & 0.395 & 0 & 1 \\
\hline latONT & Late arrival at Ontario & 0.042 & 0.200 & 0 & 1 \\
\hline latSNA & Late arrival at Santa Anna & 0.005 & 0.070 & 0 & 1 \\
\hline
\end{tabular}


Table 1 provides definitions and summary statistics for the explanatory variables, separately for business and leisure travelers. Airport choice is explained by dummy variables for departure and for arrival airport, as we expect that the other explanatory variables do not capture all relevant airport characteristics. The dummies for United Airlines (UA) and Southwest Airlines (WN) are introduced because fare variation between carriers does not capture all, or even the most important, reasons why these carriers are chosen; other relevant characteristics include consumer loyalty programs and airport dominance (at the time of study, UA dominated SFO, and WN dominated OAK). We also include dummy variables to indicate the earliest and latest arriving flights at the four L.A. region airports. ${ }^{14}$ Passengers flying from the Bay Area to L.A. may prefer early flights as this maximizes the length of stay of short duration trips. Evening flights may be disliked because no later same day flights may be available in case the flight is missed.

The continuous explanatory variables are flight frequency, ground access time to the airport, airport delays, and the fare as well as the interaction between fare and passengers' income group. Flight frequency is measured at the airport - airline - period level, and indicates quality of service. Ground access times are defined at the airport period level, and are part of the overall cost of using a particular airport. Airport delays are measured at the airport level, and co-determine service quality. Fares are part of the cost of flying, and we allow the fare effect to depend on income levels.

Controlling for a fairly large set of demand characteristics helps limit the problem of endogeneity of fares and travel delay, stemming from omitted factors. However, there are other complications associated with fares. First, the airfare used to evaluate the indirect utility associated with a flight option is not the actual transaction airfare faced by the surveyed passenger, but rather the average transaction airfare for that flight during the studied period. Second, we do not observe when the passenger purchased her ticket. The choice set is based on what we observe ex post and not necessarily what was available to the passenger at the time of the booking. We partially address this complication by estimating a separate model for leisure and business travelers, as the choice set is more likely to be common among travelers of similar trip type, with leisure travelers more likely

${ }^{14}$ Early and late arrival times are airport-specific. For example, the earliest arrival 7.30am at SNA, 6.00am at BUR, and 6.30am at LAX. 
to buy their tickets in advance and business on short notice. Nevertheless, the complications suggest that the strength of the empirical model is in analyzing the role of non-price airport and airline characteristics in air travel choice, controlling for general fare differences, rather than the estimation of particular own and cross price elasticities or values of time.

Table 2 reports estimation results for the basic specification, separately for business and leisure travelers; Table 2a provides coefficient estimates and standard errors; Table 2b shows marginal effects, which can be compared across subgroups. ${ }^{15,16}$ With the exception of some fare related coefficients and a few dummy variables, the coefficients are estimated with good precision, and the signs of the effects correspond to intuition. Alternatives with lower prices, lower access costs, shorter delays and higher flight frequencies are more likely to be chosen than others. The effect of fares on business travel decisions is not found to differ from zero. This may reflect our use of average rather than actual fares, but it also is plausible that business travelers do not strongly respond to fare differences in deciding how to travel. The airport dummies are precisely estimated and significant. SFO is the preferred departure airport and LAX is the preferred destination airport, ceteris paribus. Passengers are also more likely to choose an airport that is served by Southwest Airlines or by United Airlines, although the latter effect is not precisely estimated for leisure travelers. Note that this preference is over and above Southwest's low fares and United Airlines' high frequency of services from SFO to LAX. ${ }^{17}$ The results seem consistent with the

15 The results are for the weighted conditional logit model. Coefficient estimates for the unweighted model can be found in the appendix. As suggested by Manski and Lerman (1977), the coefficient estimates between the two models differ mainly in the choice specific intercepts. However, since the marginal effects are a function of all of the coefficients including the airline and airport dummies, they differ substantially for all of the included airline and airport characteristics as well. For many marginal effects, ignoring the choice based sampling leads to values that are roughly half of those obtained from a weighted model.

16 The marginal effects are "own characteristic marginal effects”, i.e. the partial derivatives of the probability of the actual choice with respect to a change in that choice's characteristic, taking account of the presence of any interaction terms. For dummy variables, the marginal effects are defined as probability differences. Appendix 2 provides more details.

17 The October 1995 survey reports a 75\% market share of UA at SFO (USair: 15\%, Delta: 7\%). UA has a market share of $18 \%$ at OAK and is not present at SJC. Southwest dominates both OAK (75\%) and SJC 
"Southwest effect" and "hub-dominance effect", as identified in earlier empirical analyses of the airline industry. The "early flight" dummies for LAX are positive and precisely estimated for both types of traveler, indicating that passengers value arriving in LAX in the early morning. This result was expected because the length of stay for travel to LAX and originating in the Bay Area is often short, e.g. one or two days. In that case, arriving early allows travelers to spend a full day at their destination, even on the day of departure. The effect is imprecisely estimated for BUR. The estimate for SNA is precise, but smaller than for LAX and ONT, which may reflects flight time restrictions at SNA, because of which the early flights to SNA arrive later in the day than at other airports. Late flights are valued negatively, but the effects are not precisely estimated. So there is only weak evidence that passengers avoid late flights in order to minimize the risk of having to wait until the next day. ${ }^{18}$

Table $2 \mathrm{~b}$ shows marginal effects, which can be compared between business and leisure travelers. The results for both are largely similar, but there are some noticeable differences as well. For example, the preferred airports differ substantially. The marginal effect on the probability that a flight departing from SJC is chosen rather than one from SFO, after controlling for observable airport characteristics, is negative but much stronger for leisure travelers than for business travelers. The reverse relation holds for the marginal effect on the choice probabilities of choosing a flight from OAK rather than SFO. The results suggest that SFO and OAK are close substitutes, in particular for leisure travelers. SJC is a relatively close substitute for SFO for business travelers, but less so for leisure travelers.

(85\%). It is not present at SFO. In terms of arrival airports, Southwest dominates BUR (82\%), ONT (94\%) and SNA (56\%). UA carries $18 \%$ of passengers at BUR, $23 \%$ at LAX, $6 \%$ at ONT and $11 \%$ at SNA.

${ }^{18}$ Anecdotical evidence suggests that the last daily flight is rarely cancelled. The risk of not getting to L.A. then is not related to potential cancellations, but to decisions under the passengers' control, in which case a weak effect is to be expected because passengers can take precautions to not miss the flight. 
Table 2a WESML estimation results for conditional logit model, October 1995

\begin{tabular}{|l|c|c|c|c|}
\hline \multirow{2}{*}{} & \multicolumn{2}{|c|}{ Business } & \multicolumn{2}{c|}{ Leisure } \\
\cline { 2 - 5 } & Coeff. & std. error & Coeff. & std. error \\
\hline SJC dummy & -0.6514 & 0.2973 & -1.0901 & 0.3050 \\
OAK dummy & -0.6900 & 0.2176 & -0.4176 & 0.2007 \\
WN dummy & 1.0990 & 0.1712 & 1.0694 & 0.2124 \\
UA dummy & 0.5043 & 0.1985 & 0.2406 & 0.1889 \\
BUR dummy & -0.1827 & 0.1725 & -0.4590 & 0.1764 \\
ONT dummy & -0.4092 & 0.2051 & -0.8486 & 0.2185 \\
SNA dummy & -0.3936 & 0.1996 & -0.9105 & 0.2581 \\
\hline fare & -0.0077 & 0.0089 & -0.0259 & 0.0102 \\
freq_hour & 0.4168 & 0.1071 & 0.6322 & 0.2127 \\
accetime & -0.0815 & 0.0043 & -0.0774 & 0.0044 \\
tdelay & -0.0498 & 0.0155 & -0.0257 & 0.0158 \\
incgroup2 & 0.0040 & 0.0080 & 0.0208 & 0.0093 \\
incgroup3 & 0.0029 & 0.0077 & 0.0088 & 0.0111 \\
\hline earBUR & 0.2614 & 0.2816 & -0.0726 & 0.3099 \\
earLAX & 0.6163 & 0.2624 & 0.5644 & 0.2417 \\
earONT & 0.7024 & 0.2824 & 0.7705 & 0.2661 \\
earSNA & 0.3166 & 0.2879 & 0.3267 & 0.3636 \\
latBUR & -0.3181 & 0.3099 & -0.0196 & 0.2596 \\
latLAX & -0.2420 & 0.2098 & -0.3260 & 0.2083 \\
latONT & -0.5641 & 0.2622 & 0.1165 & 0.2706 \\
latSNA & 0.7275 & 0.3573 & -0.2893 & 0.5816 \\
\hline Number of Obs & \multicolumn{2}{|c|}{935} & \multicolumn{2}{c}{817} \\
\hline \multicolumn{1}{|c|}{ Log LL } & $-2,677.19$ & & $-2,555.43$ \\
\hline
\end{tabular}

Table $2 b$ Marginal effects (change in probability) for conditional logit model, October 1995

\begin{tabular}{lcc}
\hline Variable & Business & Leisure \\
\hline sjc & -2.787 & -5.307 \\
oak & -2.499 & -1.257 \\
wn & 4.450 & 5.970 \\
ua & -0.650 & -2.322 \\
bur & -0.266 & -1.720 \\
ont & -1.582 & -4.125 \\
sna & -1.613 & -3.763 \\
fare & -0.024 & -0.091 \\
freq & 2.368 & 4.241 \\
accetime & -0.463 & -0.519 \\
tdelay & -0.283 & -0.172 \\
incgroup2 & 1.193 & 8.072 \\
incgroup3 & -0.073 & -0.490 \\
earBUR & 0.021 & -0.005 \\
earLAX & 0.360 & 0.447 \\
earONT & 0.072 & 0.096 \\
earSNA & 0.014 & 0.010 \\
latBUR & -0.044 & -0.004 \\
latLAX & -0.374 & -0.769 \\
latONT & -0.121 & 0.026 \\
latSNA & 0.165 & -0.004 \\
\hline Number of Passengers & 935 & 817 \\
\hline
\end{tabular}


Table 3 Weighted Mixed logit estimation results: Weekday travel, October 1995 - UPDATE

\begin{tabular}{|c|c|c|c|c|c|}
\hline \multirow{2}{*}{ Distribution assumption } & \multirow{2}{*}{ Variable } & \multicolumn{2}{|c|}{ Business } & \multicolumn{2}{|c|}{ Leisure } \\
\hline & & coeff. & std.error & coeff. & std.error \\
\hline \multirow{14}{*}{ Normal Distribution } & SJC mean & -0.7091 & 0.2624 & -1.5993 & 0.2958 \\
\hline & SJC std & 0.0022 & 0.0092 & 0.0191 & 0.0404 \\
\hline & OAK mean & -0.6637 & 0.2025 & -0.4334 & 0.1818 \\
\hline & OAK std & 0.0080 & 0.0093 & 0.0117 & 0.0391 \\
\hline & WN mean & 1.1066 & 0.2198 & 1.2861 & 0.3566 \\
\hline & WN std & 0.0291 & 0.0255 & 1.0544 & 1.0392 \\
\hline & UA mean & 0.5223 & 0.1990 & 0.0432 & 0.3631 \\
\hline & UA std & 0.0116 & 0.0234 & 1.4641 & 1.2924 \\
\hline & fare mean & -0.0094 & 0.0141 & -0.0214 & 0.0142 \\
\hline & fare std & 0.0084 & 0.0145 & 0.0000 & 0.0027 \\
\hline & freq mean & 0.4205 & 0.1301 & 0.7191 & 0.2232 \\
\hline & freq std & 0.0228 & 0.0400 & 0.0429 & 0.0774 \\
\hline & Accetime mean & -0.1023 & 0.0096 & -0.1314 & 0.0179 \\
\hline & Accetime std & 0.0451 & 0.0101 & 0.0820 & 0.0150 \\
\hline \multirow{14}{*}{ Fixed Coefficients } & BUR & -0.2262 & 0.1649 & -0.5614 & 0.1696 \\
\hline & ONT & -0.4742 & 0.2046 & -0.9874 & 0.2123 \\
\hline & SNA & -0.4350 & 0.2135 & -1.1700 & 0.2561 \\
\hline & tdelay & -0.0539 & 0.0150 & -0.0484 & 0.0167 \\
\hline & Inc2 & 0.0044 & 0.0085 & 0.0203 & 0.0133 \\
\hline & Inc3 & 0.0030 & 0.0075 & 0.0050 & 0.0100 \\
\hline & earBUR & 0.3559 & 0.2479 & 0.1384 & 0.2884 \\
\hline & earLAX & 0.6640 & 0.2424 & 0.6705 & 0.2335 \\
\hline & earONT & 0.8050 & 0.2700 & 1.0836 & 0.2774 \\
\hline & earSNA & 0.3996 & 0.2284 & 0.6253 & 0.3204 \\
\hline & latBUR & -0.3295 & 0.5255 & -0.1009 & 0.4708 \\
\hline & latLAX & -0.2868 & 0.1964 & -0.3883 & 0.1848 \\
\hline & latONT & -0.5820 & 0.3271 & 0.0172 & 0.3385 \\
\hline & latSNA & 0.6820 & 0.4576 & -0.3265 & 0.6168 \\
\hline $\operatorname{LogL}$ & & \multicolumn{2}{|c|}{-2669.3487} & \multicolumn{2}{|c|}{-2521.8066} \\
\hline Number of Obs & & \multicolumn{2}{|c|}{935} & \multicolumn{2}{|c|}{817} \\
\hline
\end{tabular}


A puzzling result is the finding that leisure travelers seem to care more about flight frequency than business travelers. Lastly, while business travelers value time spent accessing the airport and on flight delays roughly the same, leisure travelers seem to care more about access time. This may be due to the fact that opportunity cost of time for business travelers is foregone work time, while for leisure travelers the disutility of spending time in traffic vs. waiting at the airport is more important. Other possible explanations include differences in risk aversion, with higher access time indicating greater chance of missing flights, differences in information set, with business travelers better perceiving both access time and travel delay, and the greater hassle of dealing with children in cars than at the airport.

Table 3 presents the corresponding estimates from a weighted "mixed logit" model where we allow some coefficients to vary randomly according to a normal distribution, so allowing for unobserved variation in preferences. ${ }^{19}$ We mix the three departure airport dummies, the two airline dummies, and the two "value of time" characteristics of access time and travel delay. Estimation difficulties prevent us from estimating a more generally mixed model. With the exception of the airline dummies for leisure travelers, the weighted mixed logit yields results are similar to those from the weighted conditional logit. The random coefficients are largely centered at the conditional logit estimates with small estimated standard deviations. This result contrasts those reported in other airport choice studies (in particular Hess and Polak, 2005) and suggests that our focus on a single market and trip type accounts for much of the consumer preference heterogeneity in the sample. ${ }^{20}$ The large variation in preference for airlines by leisure travelers probably reflects the adoption of different frequent flyer programs. ${ }^{21}$ However, the large standard deviations are estimated imprecisely. We find little evidence suggesting that a mixed logit model substantially outperforms the conditional logit model after controlling for market and trip type. On the basis of this judgment, we calculate the

\footnotetext{
${ }^{19}$ See Train (2003) for more details on the Mixed Logit model. The asymptotic properties of the weighted mixed logit models are based on results in Wooldridge (2001)

${ }^{20}$ We found the mixed logit results to be robust to different initial values.

${ }^{21}$ Analogously, the small standard deviation for the mixing distribution for airlines for business travelers suggests most business travelers have similar frequent flyer participation.
} 
counterfactual scenarios using the weighted conditional logit estimates.

\section{Counterfactual scenarios}

This section reports on three counterfactual scenarios that were calculated using the conditional logit model presented in the previous section. The purpose is to provide further insight into the role of airport characteristics and airline behavior on the market under consideration, taking account of the model as a whole rather than its separate coefficients. The first two scenarios highlight the importance of time costs in airport and airline choice. In the first scenario (Access SFO) ground access times to SFO are reduced by 5 minutes. In the second scenario (Delay SFO) delays for flights from SFO are reduced by 5 minutes. The third scenario (Southwest SFO) has more of an IO flavor, as it considers the effect of entry by Southwest Airlines into SFO. Since we have no explicit model of supply, four polar cases of the scenario are calculated: in version A (duplicate, accomodate) Southwest duplicates its 1995 operation at OAK in SFO and there is no price response from UA (its main competitor); in version B (transfer, accommodate) Southwest transfers its entire OAK operation to SFO, and UA sticks to its prices. In version C (duplicate, match) Southwest duplicates in SFO and there is UA responds by adopting Soutwest's prices; in version D (transfer, match) Southwest transfers its operation from OAK to SFO, and UA adopts the Southwest prices. In all versions, Southwest charges the same prices at SFO than it in fact charged at OAK, and airlines other than United Airlines do not change their prices and service levels. ${ }^{22}$

Table 4 compares the results from the counterfactual scenario to the predicted values of the estimated model (baseline) rather than to the observed values. We report market shares for business, leisure, and all passengers. The random error term is assumed to be the same, at the level of an observation, in the baseline and in the counterfactual scenario. The scenarios take the decision to travel by air as given, so they only consider substitution between travel alternatives in response to a change in travel options or travel costs, abstracting from substitution effects with an outside good. This may be a reasonable assumption for business travelers, whose demand for air travel is fairly

\footnotetext{
22 Ito and Lee (2004) find incumbent response to low cost carrier entry to be fairly accommodating.
} 
inelastic. $^{23}$

Table 4 Key results for counterfactual scenarios: percentage market shares *

\begin{tabular}{|c|c|c|c|c|c|c|c|}
\hline \multirow[t]{2}{*}{ Model } & \multirow[t]{2}{*}{ Baseline } & \multirow[t]{2}{*}{$\begin{array}{l}\text { Access } \\
\text { SFO }\end{array}$} & \multirow[t]{2}{*}{$\begin{array}{l}\text { Delay } \\
\text { SFO }\end{array}$} & \multicolumn{2}{|c|}{$\begin{array}{l}\text { Southwest SFO } \\
\text { UA accommodates }\end{array}$} & \multicolumn{2}{|c|}{$\begin{array}{l}\text { Southwest SFO } \\
\text { UA matches }\end{array}$} \\
\hline & & & & Duplicate & Transfer & Duplicate & Transfer \\
\hline & & & & A & $\mathrm{B}$ & $\mathrm{C}$ & $\bar{D}$ \\
\hline Leisure only & & & & & & & \\
\hline$\%$ from SFO & 27.1 & 33.5 & 29.1 & 46.5 & 66.2 & 62.4 & 78.6 \\
\hline \% from SJC & 20.0 & 18.4 & 19.5 & 15.4 & 19.1 & 11.3 & 13.0 \\
\hline$\%$ from OAK & 53.0 & 48.1 & 51.4 & 38.1 & 14.7 & 26.3 & 8.4 \\
\hline$\%$ with UA & 29.5 & 33.5 & 30.8 & 18.6 & 29.6 & 46.0 & 59.3 \\
\hline \% with WN & 57.8 & 52.7 & 56.2 & 73.0 & 58.8 & 48.4 & 33.8 \\
\hline \% with other & 12.7 & 13.8 & 13.0 & 8.4 & 11.6 & 5.6 & 6.9 \\
\hline $\begin{array}{l}\text { Business } \\
\text { only }\end{array}$ & & & & & & & \\
\hline$\%$ from SFO & 31.4 & 37.7 & 35.2 & 45.0 & 56.6 & 49.1 & 60.1 \\
\hline$\%$ from SJC & 36.1 & 33.8 & 34.8 & 31.1 & 34.7 & 29.4 & 32.4 \\
\hline$\%$ from OAK & 32.5 & 28.4 & 30.0 & 24.0 & 8.8 & 21.5 & 7.5 \\
\hline \% with UA & 32.7 & 37.5 & 35.6 & 20.6 & 27.8 & 28.5 & 36.4 \\
\hline$\%$ with WN & 54.1 & 49.1 & 51.1 & 69.3 & 60.1 & 62.3 & 52.7 \\
\hline \% with other & 13.2 & 13.4 & 13.3 & 10.1 & 12.1 & 9.2 & 10.9 \\
\hline $\begin{array}{l}\text { All } \\
\text { passengers }\end{array}$ & & & & & & & \\
\hline$\%$ from SFO & 29.3 & 35.7 & 31.4 & 45.9 & 61.1 & 55.4 & 69.0 \\
\hline$\%$ from SJC & 28.1 & 26.3 & 27.5 & 23.2 & 26.9 & 20.0 & 22.4 \\
\hline$\%$ from OAK & 42.5 & 38.0 & 41.0 & 30.9 & 12.0 & 24.7 & 8.6 \\
\hline \% with UA & 31.1 & 35.5 & 32.6 & 19.5 & 28.4 & 36.7 & 47.1 \\
\hline \% with WN & 55.9 & 50.8 & 54.2 & 71.4 & 60.0 & 56.2 & 44.1 \\
\hline \% with other & 13.0 & 13.7 & 13.2 & 9.1 & 11.6 & 7.1 & 8.8 \\
\hline
\end{tabular}

* The results are based on the models estimated on the entire sample and on subsamples for business travelers or leisure travelers. The reported shares are the weighted average across the 500 simulations, with weights equal to those of the estimation model. For the common choices, the same shocks were used for all 5 cases. For SFO Southwest, additional shocks were generated for the new choices (SFO-WN). The rationale is that the shocks are largely unobserved passenger characteristics.

${ }^{23}$ For those scenarios that involve reduced air travel costs, the counterfactuals provide a lower bound for the favorable change in demand for SFO and SFO-based carriers (UA), as some consumers who previously chose not to fly may be induced to fly due to the improved choices offered at SFO. The counterfactual involving Southwest transferring its operation from OAK to SFO does not provide intuitive bounds as some travelers' observed choices are altered while new options are introduced. 
Reducing access times at SFO by five minutes increases the market share of SFO from $29 \%$ to $36 \%$. The effect of reducing delays also is positive, but smaller (the SFO market share rises to 31\%). The more limited effect of reducing delays is as expected, as reducing access times by five minutes reduces the total time cost of travel by 5 minutes, while reducing delays reduces deviations from the schedule but does not necessarily imply

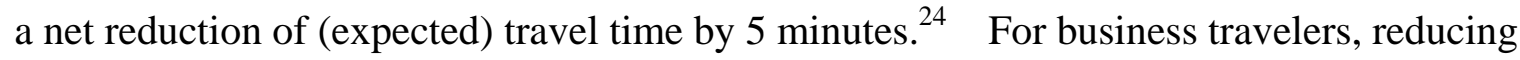
access times increases the SFO market share by 20\%, and reducing delays increases it by $12 \%$. For leisure travelers, lower access times lead to a $24 \%$ increase, while shorter delays induce a rise of only 7\% in SFO's market share. This suggests that both business and leisure travelers care about access time more than about delays, but business travelers attach a relatively higher value to delays than leisure travelers. Reducing time costs of departing from SFO leads to lower market shares both at OAK and at SJC, but the loss is larger at OAK. Since UA dominates SFO, lower time costs for using SFO lead to an increased market share for UA (for both passenger types), mainly at the expense of Southwest.

Entry of Southwest at SFO has potentially large effects on its market share, depending on UA's reaction. If Southwest enters at SFO and retains its operation at OAK, and UA accommodates, the market share of Southwest increases from 56\% to $71 \%$. But if UA matches Southwest's prices, such duplication hardly affects Southwest's market share. ${ }^{25}$ Inspection of the effects by type of traveler shows that price matching under duplication leads to an increase of Southwest's business market share (from 54\% to 62\%), and a reduction of its share in the market for leisure travel (from 58\% to 48\%). If Southwest abandons OAK in favor of SFO, price matching by UA leads to a reduction of Southwest's market share (to 48\%). The loss is large in the market for leisure travel, and small in the market for business travel. These scenarios suggest that leisure passengers have a preference for a bundle consisting of cheap travel departing from OAK. Business

\footnotetext{
24 The relative change is larger for delays than for access times, as the average access time is 25 minutes and the average delay is 11 minutes.

${ }^{25}$ None of these scenarios indicate irrational behavior on Southwest's behalf, as we neglect any costs associated with duplicating or transferring operations.
} 
travelers prefer SFO to OAK but leisure travelers like OAK more than SFO, ${ }^{26}$ which suggests that leisure travelers have a strong preference for the better access time and/or lower travel delay at OAK relative to SFO. Note, lastly, that entry of Southwest at SFO leads to a strong increase of SFO's market share (from $29 \%$ to $46 \%$ or $69 \%$, depending on the version). This is mainly at OAK's expense, but SJC loses a bit of market share as well (since more options now are available at the most preferred airport).

\section{Conclusion}

We estimate a weighted conditional logit model of airport and airline choice in the market for air travel from the San Francisco Bay Area to greater Los Angeles. We extend the existing literature that has studied airport choice using the same data source, by considering additional explanatory variables and by showing how controlling for market and trip type can account for much of the heterogeneity in consumer preference and how the choice based sampling characterizing the data can alter policy inferences drawn from the data. We interpret the estimation results from our model by considering marginal effects and counterfactual scenarios. Changing the generalized costs of using a departure airport, whether in terms of access times or expected delays, strongly affects the market shares of departure airports, but the effects of access times are larger. Business travelers are relatively more responsive to changes in delays. Entry of Southwest at SFO affects the market share of departure airports as well as that of airlines. The results suggest that leisure travelers have a preference for departing from OAK.

\section{References}

Ashford N. and Bencheman M., 1987,“Passengers’ choice of airport: an application of the multinomial logit model, Transportation Research Record 1147, 1-5

Basar G. and C.R. Bhat, 2002, A parameterized consideration set model for airport choice: an application to the San Francisco Bay area, Technical paper, Department of Civil Engineering, University of Texas at Austin

Basar G. and C.R. Bhat, 2004, A parameterized consideration set model for airport choice:

\footnotetext{
26 This does not contradict the finding of a negative SFO dummy for the leisure model as the dummy reflects the relative preference for SFO after controlling for observable airport characteristics.
} 
an application to the San Francisco Bay area, Transportation Research Part B, Vol. 38, No. 10, pp. 889-904

Berry S., 1992, Estimation of a model of entry in the airline industry, Econometrica, 60, 4, 889-917

Berry S., 1990, Airport presence as product differentiation, American Economic Review Papers and Proceedings, 80, 2, 394-399

Berry S., M. Carnall, and P. Spiller, 1997, Airline hubs: markups and the implication of customer heterogeneity, mimeo, Yale University

Borenstein S., 1989, Hub and high Fares: dominance and market power in the U.S. airline industry, Rand Journal of Economics, 20, 3, 344-365

Borenstein S., 2005, U.S. domestic airline pricing, 1995-2004, Competition Policy Center Working Paper 05’048, U.C. Berkeley

Brueckner J. and P. Spiller, 1994, Economies of traffic density in the deregulated airline industry, Journal of Law and Economics, 37, 2, 379-415

Evans, W. and I. Kessides, 1993, Localized market power in the U.S. airline industry, Review of Economics and Statistics,75, 1, 66-75

FAA/OST, 1999, Airport business practices and their impact on airline competition, FAA/OST Task Force Study

Goolsbee, A. and C. Syverson, 2005, How do incumbents respond to the threat of entry? Evidence from major airlines, NBER Working Paper 11072

Harvey G., 1987, Airport choice in a multiple airport region, Transportation Research, 21A (6), 439-449

Hess S. and J.W. Polak, 2005, Mixed logit modeling of airport choice in multi-airport regions, Journal of Air Transport Management, 11 (2), pp.59-68

Ito H. and D. Lee, 2004, Incumbent responses to lower cost entry: evidence from the U.S. airline industry, mimeo

Januszewski S., 2003, The effect of air traffic delays on airline prices, mimeo, University of California at San Diego

Manski C.F. and S.R. Lerman, 1977, The estimation of Choice Probabilities from Choice Based Samples, Econometrica, Vol. 45, No. 8, 1977-1988

Mayer C. and T. Sinai, 2003, Network effects, congestion externalities, and air traffic 
delays: or why not all delays are evil, American Economic Review, 93, 4,1194-1215

Mazzeo M., 2003, Competition and service quality in the U.S. airline industry, Review of Industrial Organization, 22, 275-296

Morrison S.A. and C. Winston, 1989, Enhancing the performance of the deregulated air transportation system, Brookings Papers on Economic Activity, Microeconomics, Vol. 1989, 61-123

Morrison S.A., 2001, Actual, adjacent, and potential competition - Estimating the full effect of Southwest Airlines, Journal of Transportation Economics and Policy, 35, 2, 239-256

Pels E., P. Nijkamp and P. Rietveld, 2001, Airport and airline choice in a multi-airport region: an empirical analysis for the San Francisco Bay area, Regional Studies, 35, 1, $1-9$

Pels E., P. Nijkamp and P. Rietveld, 2003, Access to and competition between airports: a case study for the San Francisco Bay area, Transportation Research 37A, 71-83

Skinner R.E. Jr., 1976, Airport choice: an empirical study, Transportation Engineering Journal, 102, 871-883

Train K., 2003, Discrete choice methods with simulation, Cambridge University Press

Van Dender K., 2005, Duopoly prices under congested access, Journal of Regional Science, 45, 2, 343-362

Van Dender K., 2006, Determinants of fares and operating revenues of large U.S. airports, U.C. Irvine, mimeo

Wooldridge, J.M., 2001, Asymptotic properties of weighted M-estimators for standard stratified samples, Econometric Theory, 17, 451-470

\section{Appendix 1 Construction of the variables}

1. ACC_T: airport access time by car

- Find which TAZ matches to SFO, SJC, and OAK

The MTC airline passenger survey records the travel analysis zone (TAZ) for each passenger who was interviewed. The MTC maintains a set of travel analysis zones for use in MTC planning studies. These TAZs are typically small area neighborhoods or 
communities that serve as the smallest geographic base for travel demand modelforecasting systems. The zone system used in the MTC survey is the 1099 zone system developed in 1993. The MTC 1099 zone is equivalent to the 1990 census tract. The 1990 census tract information can be found in Bay area census website (www.bayareacensus.ca.gov). From the file which compares TAZ and census tract (ftp://ftp.abag.ca.gov/pub/mtc/), SFO, SJC, and OAK match “165”, “323”, and “647” respectively.

- Use "Zone-to-Zone travel times and distances for auto" data to get "ACC_T" We find travel times depending on which time of day a passenger drives and on the vehicle occupancy rate. For example, if a passenger drives during peak hours and reports that two people were in vehicle, we use peak-hour driving time for ride 2.

2. FREQ: frequency of service Using OAG data, we first calculate the number of flights depending on the departure time and the day of week. We count the number of flights within peak hours (6-9 AM and 3-6 PM) or off-peak hours (all remaining hours). Then we divided the number of flights by 6 or by 18 to get frequency per hour.

3. FARE

We use Severin Borenstein's DB1A fourth quarter 1995 average fares for direct flights

4. DEL_T

The departure and arrival delays for all flights flown out of (SFO, SJC, OAK) to (BUR, LAX, ONT, SNA) for (August, October) of 1995 were used to calculate the monthly mean departure delay and the monthly mean arrival delay for each combination of origin and destination airport. DEL_T is the sum of average departure delay and arrival delay by peak and off-peak. Cf. http://www.transtats.bts.gov

\section{Appendix 2 Marginal Effects Calculation}

The average marginal effects reported in Table $2 b$ are based on the "own characteristic" marginal effects of each sampled traveler's observed choice. The marginal effects are calculated in the manner described below for each sampled traveler. The marginal effects are then averaged using the same weights as in estimation. The weights 
help extrapolate the average to the population, rather than the sample (which overrepresents travelers choosing San Jose Airport).

For airline/airport characteristics that are continuous, the own characteristic marginal effect is the probability derivative, $\beta_{\mathrm{k}} \mathrm{P}_{\mathrm{ij}}\left(1-\mathrm{P}_{\mathrm{ij}}\right)$, where $\beta_{\mathrm{k}}$ is the estimated coefficient for characteristic $k$ and $P_{i j}$ the estimated probability of traveler $i$ choosing observed choice j. For airfare, the income interaction is properly incorporated into the derivative calculation.

For discrete airline/airport characteristics, the own characteristic marginal effect is the discrete difference in the estimated probability of the observed choice.

For airport dummies, it is the difference in the estimated probability assuming the observed choice flew out of the considered airport versus the estimated probability assuming the observed choice flew out of the actually observed airport. In the case where the actual and considered airports are the same, the actual airport is substituted with the excluded airport (SFO for departure airports and LAX for arrival airports). All other airport/airline characteristics are held the same as the observed choice.

For airline dummies, it is the difference in the estimated probability assuming the observed choice was with the considered airline versus the estimated probability assuming the observed choice was with the actually observed airline. In the case where actual and considered airlines are the same, the actual airport is substituted with the excluded airline (non-Southwest, non-United). All other airport/airline characteristics are held the same as the observed choice. 


\section{Appendix 3: Unweighted conditional logit estimates}

\begin{tabular}{|c|cc|cc|cc|}
\hline \multirow{2}{*}{} & \multicolumn{2}{|c|}{ All } & \multicolumn{2}{c|}{ Business } & \multicolumn{2}{c|}{ Leisure } \\
\cline { 2 - 7 } & Coef. & Std. error & Coef. & Std. error & Coef. & Std. error \\
\hline sjc & 0.1428 & 0.1718 & 0.4281 & 0.2547 & -0.1598 & 0.2534 \\
oak & -0.0106 & 0.1265 & -0.1418 & 0.1952 & 0.0118 & 0.1793 \\
un & 1.1582 & 0.1103 & 1.0094 & 0.1494 & 1.0188 & 0.1837 \\
burbank & 0.4241 & 0.1140 & 0.4180 & 0.1784 & 0.1552 & 0.1680 \\
ont & -0.3968 & 0.0996 & -0.2276 & 0.1414 & -0.5619 & 0.1477 \\
oc & -0.6469 & 0.1196 & -0.3662 & 0.1666 & -0.8519 & 0.1792 \\
fare & -0.5646 & 0.1265 & -0.3214 & 0.1652 & -0.8142 & 0.2139 \\
freq_hour & -0.0270 & 0.0066 & -0.0178 & 0.0091 & -0.0396 & 0.0106 \\
accetime & 0.3339 & 0.0754 & 0.5174 & 0.0998 & 0.8781 & 0.2040 \\
tdelay & -0.0808 & 0.0026 & -0.0777 & 0.0035 & -0.0815 & 0.0039 \\
incgroup2 & -0.0341 & 0.0088 & -0.0556 & 0.0128 & -0.0396 & 0.0133 \\
incgroup3 & 0.0147 & 0.0059 & 0.0027 & 0.0078 & 0.0174 & 0.0094 \\
earBUR & 0.0105 & 0.0061 & 0.0091 & 0.0077 & 0.0151 & 0.0115 \\
earLAX & 0.3161 & 0.1674 & 0.4809 & 0.2251 & 0.0936 & 0.2541 \\
earONT & 0.8128 & 0.1424 & 0.7219 & 0.2142 & 0.4924 & 0.2052 \\
earSNA & 0.9682 & 0.1546 & 0.9712 & 0.2212 & 0.9192 & 0.2175 \\
latBUR & 0.5037 & 0.1661 & 0.4992 & 0.2160 & 0.6248 & 0.2643 \\
latLAX & -0.8912 & 0.2639 & -1.0131 & 0.4267 & -0.7636 & 0.3392 \\
latONT & -0.1040 & 0.1112 & -0.2267 & 0.1661 & -0.3803 & 0.1678 \\
latSNA & 0.6984 & 0.2895 & 1.3110 & 0.3778 & 0.3721 & 0.6220 \\
\hline Number of Obs & \multicolumn{2}{|c|}{1752} & & & & \\
\hline Log LL & -5146.5655 & -2745.2628 & & -2354.6147 \\
\hline
\end{tabular}

